\title{
Cold Flow Properties and Kinematic Viscosity of Biodiesel
}

\author{
Nwadike Isioma, Yahaya Muhammad, O’Donnell Sylvester, Demshemino Innocent, Okoro Linus*
}

\author{
Department of Petroleum Chemistry and Engineering, School of Arts and Sciences, American University of Nigeria, Lamido Zubairu Way, \\ Yola By-Pass, P.M.B. 2250 Yola, Adamawa State, Nigeria \\ *Corresponding Author: linus.okoro@aun.edu.ng
}

Copyright (C 2013 Horizon Research Publishing All rights reserved.

\begin{abstract}
Biodiesel is a substitute diesel fuel produced from vegetable oils or animal fats by trans-esterification in the presence of a catalyst. Due to its environmental friendliness, its use is becoming necessary in all regions, however, there are problems associated with its fluidity in cold temperatures. This paper examines the cold flow properties as well as the kinematic viscosity of produced biodiesels. The review shows that both properties are affected by the length of the carbon chain and degree of saturation. However, these can be improved by blending either with petro-diesel or less saturated FAME, as well as the use of some additives.
\end{abstract}

Keywords Kinematic Viscosity, Biodiesel Specification, Fatty Acid Methyl Ester, Cold Flow

\section{Introduction}

Biodiesel is a form of diesel fuel consisting of fatty acid methyl esters (FAME) or ethyl esters, obtained from vegetable oils or animal fats. It is made from oils or fats using trans-esterification reaction, and it is similar to mineral diesel in composition $[1,2]$.

One of the distinguishing traits of biodiesel as compared to other biofuels is the fact that it can be produced from different forms of feedstock [3]. Biodiesel Feedstock includes; palm oil, vegetable oils, soybean, rapeseed, jatropha, mustard, algae, flaxseed, sunflower, hemp, tallow, lard yellow grease and animal fats. Pure biodiesel (B100) is the lowest-emission diesel fuel [2]. However, the lard, yellow grease and tallow biodiesels need further processing at the end of trans-esterification to attain satisfactory biodiesel standard, and processing before trans-esterification will reduce or eliminate components that may interfere [4].

Soy biodiesel is mostly used in the United States, while that of canola is prevalent in Europe. It is mixed with petro-diesel to get many of the beneficial properties to diesel equipment, and the cost of fuel is reduced [4].

In the production of biodiesel, the main quality control measures involve the thorough or almost complete elimination of unreacted or partially reacted triglycerides, catalyst, free fatty acids, soaps, glycerin, alcohol and water, without which these contaminants will cause the methyl ester product to fall short of fuel standards [4].

The major advantage of biodiesel as compared to petro-diesel is that it is renewable. Though the biodiesel renewability is strongly a fact in respect to the contribution of the transportation sector to increasing global warming, other issues as biodiversity and food prices should not be neglected [3].

Biodiesel is generally considered to be environmentally friendly [5]. Using biodiesel in existing diesel engines significantly reduces particulate matter (PM), carbon monoxide ( $\mathrm{CO}$ ), and unburned hydrocarbons ( $\mathrm{HC})$, but increases nitrogen oxides (NOx) slightly. Because it is biodegradable and non-toxic, its spills will cause less effect unlike those of crude oil or petro-diesel [6].

Though biodiesel has the potential for environmental emissions reduction, it also has high pour points and high viscosity compared to diesel fuel [7].

For accurate simulation of the fuel spray, emission formation processes, combustion and atomization of a diesel engine fueled with biodiesel, the knowledge of its physical properties is needed.

Being less stable than petroleum fuels, it is recommended that biodiesel be used within six months of production, as factors like exposure to some metals, air, light, heat and water can contribute to reduce its worth. A common indication of degraded fuel is plugged filters. But the shelf life can be extended with appropriate storage and the use of additives [8].

The aim of this work is to do an elaborate review of cold flow properties and kinematic viscosity of biodiesel, recommended for high performance of biodiesel as substitute fuel for diesel engines.

The Worldwide Fuel Charter (WWFC) Committee [9], provided guidelines on biodiesel standard and quality, in the subject; Worldwide Biofuels Harmonization. WWFC was established in the year 1998 to boost the understanding of the effect of fuel quality on engine performance, vehicle emissions and to encourage harmonization of fuel standard in accordance with engine and vehicle requirements in different markets worldwide.

In the guideline, it is stated that viscosity should be at or 
below $48 \mathrm{~mm}^{2} / \mathrm{s}$ for temperatures at or below $-20^{\circ} \mathrm{C}$, to avoid potentially dangerous loads, on the fuel injection pump drive system. Given that the Kinematic Viscosity at $40^{\circ} \mathrm{C}$ should be $2.0-5.02$, using EN ISO 3104, ASTM D445 and JIS K2283 test method.

The properties investigated in this review are; Cold flow properties (Cloud point CP, pour point PP and cold filter plugging point CFPP) and Kinematic viscosity, for Optimal Feedstock Selection, Processing, Refining/Blending, Storage/Transportation, and Combustion.

Table 1 contains some of these parameters and their accepted values as specified by the American Society for Testing and Materials (ASTM) standard.

The parameters for B100 fuel are specified through the biodiesel standard, ASTM D6751. This standard identifies the parameters that pure biodiesel (B100) must meet before being used as a pure fuel or being blended with petro-diesel.

Table 1. Specification for Biodiesel (B100)

\begin{tabular}{|c|c|c|c|}
\hline Property & ASTM Method & Limits & Units \\
\hline $\begin{array}{c}\text { Kinematic } \\
\text { Viscosity, } 40^{\circ} \mathrm{C}\end{array}$ & D445 & $1.9-6.0$ & $\mathrm{~mm} 2 / \mathrm{sec}$ \\
\hline Cloud Point & D2500 & $\begin{array}{c}\text { Report to } \\
\text { customer }\end{array}$ & Degrees C \\
\hline
\end{tabular}

\section{Methodology}

In order to review the cold flow properties and kinematic viscosity of biodiesel, information was carefully collected from references of individual or group of researchers and research centers, published in international Journals.

\subsection{Cold Flow Properties}

The cold flow properties are properties that describe the fluidity of biodiesel in low temperature. Biodiesel has higher cloud point/pour point compared to petro-diesel. Pure biodiesel begins to cloud at $12.78^{\circ} \mathrm{C} / 55^{\circ} \mathrm{F}$ and gel by $0^{0} \mathrm{C} / 32^{\circ} \mathrm{F}$ [8].From vegetable to animal sources, the minimum temperatures at which biodiesels are usable increases, probably due to the higher level of saturation [4]. Biodiesel from vegetable oils such as rapeseed oil has better fluidity in cold clime than beef tallow from animal fats.
Regardless of origin, all diesel fuels are liable to start-up and operability issues when vehicles and fuel systems are open to cold temperatures. At low temperatures, higher-melting point (MP) constituents in the fuel nucleate and grow to form solid wax crystals. When left overnight, these crystals may plug or restrict flow through filters causing start-up and operability problems the next morning [10].

Pérez [11] also stated that biodiesel is liable to start-up and functioning problems, consistent with its chemical makeup, when vehicles and fuel systems are exposed to cold temperatures. These Cold properties of biodiesel is assessed by the following temperatures; cloud point (CP) at which crystals begin to form, pour point (PP) at which fuel no longer pours [12] and cold filter plugging point (CFPP) at which fuel crystals begins to stop up a fuel filter. This test is regarded a better indicator of low temperature operability than cloud point [13]. All biodiesel fuels show poorer cold flow properties with higher cloud and pour points than those of petro-diesel [14].

Biodiesel in general begins to gel at higher temperatures than \#2 diesel fuels. Greases and animal fats biodiesel can crystallize at $20^{\circ} \mathrm{C}$ or even higher, while soybean oil-based biodiesel can form at about $0^{\circ} \mathrm{C}$. Biodiesel produced in low quality with an incomplete reaction can act in like manner, because the mono- and di-glycerides crystallizes even at higher temperatures [15].

The engine filter plugging due to high levels of mono-glycerides is a problem that has been observed recently with biodiesel during cold weather, this is as a result of incomplete reaction of fats and oils in producing biodiesel, though it does not give combustion problem if ASTM standards are met. However, because mono-glycerides are only fairly soluble in biodiesel, as the biodiesel becomes cold, it drops out of solution, leaving a slimy gum that clogs paper filters [13].

Many investigations have been carried out by researchers on cold properties and their effect on biodiesel performance. In a report on the Production of Biodiesels from Multiple Feedstock and Properties of Biodiesels and Biodiesel/ Diesel Blends [4] presented the following cloud points of different methyl esters and diesel.

Table 2. Measured cloud point of different MEs and Diesel

\begin{tabular}{|c|c|c|c|c|c|c|c|c|}
\hline & Soy ME & Canola ME & Lard ME & $\begin{array}{c}\text { Edible Tallow } \\
\text { ME }\end{array}$ & $\begin{array}{c}\text { Inedible } \\
\text { Tallow ME }\end{array}$ & $\begin{array}{c}\text { LFFA } \\
\text { Yellow } \\
\text { Grease ME }\end{array}$ & $\begin{array}{c}\text { HFFA } \\
\text { Yellow } \\
\text { Grease ME }\end{array}$ & $\begin{array}{c}\text { 2D } \\
\text { Diesel }\end{array}$ \\
\hline Cloud Pt, ${ }^{\circ} \mathrm{F}$ & 36 & 27 & 57 & 68 & 73 & 108 & 46 & 0 \\
\hline Cloud $\mathrm{Pt},{ }^{\circ} \mathrm{C}$ & 2 & -3 & 14 & 20 & 23 & 42 & 8 & -18 \\
\hline
\end{tabular}

SOURCE: National Renewable Energy Laboratory, Biodiesel report, March 2003, NREL/SR-510-31460 
Table 3. Measured and calculated CPs of biodiesel fuel from various oils/fats feedstock with their FA composition.

\begin{tabular}{|c|c|c|c|c|c|c|c|c|}
\hline \multirow[t]{2}{*}{ Oils/fats } & \multicolumn{6}{|c|}{ Fatty acid methyl esters (wt \%) } & \multicolumn{2}{|c|}{$\mathrm{CP}(\mathrm{K})$} \\
\hline & $\mathrm{C} 16: 0$ & $\mathrm{C} 18: 0$ & C18:1 & C18:2 & $\mathrm{C} 18: 3$ & Others & Measured & Calculated \\
\hline Linseed & 6.7 & 3.7 & 21.7 & 15.8 & 52.1 & - & 268 & 273 \\
\hline Safflower & 6.4 & 2.2 & 13.9 & 76.0 & 0.2 & 1.3 & 267 & 269 \\
\hline Sunflower & 6.1 & 4.2 & 24.0 & 63.5 & 0.4 & 1.8 & 274 & 275 \\
\hline Rapeseed & 4.3 & 1.9 & 61.5 & 20.6 & 8.3 & 3.1 & 267 & 267 \\
\hline Soybean & 10.7 & 3.2 & 25.0 & 53.3 & 5.4 & 2.5 & 272 & 273 \\
\hline Olive & 10.7 & 2.6 & 78.7 & 5.8 & 0.7 & 1.5 & 268 & 273 \\
\hline Palm & 39.5 & 4.1 & 43.2 & 10.6 & 0.2 & 2.4 & 283 & 288 \\
\hline Beef tallow & 23.9 & 17.5 & 43.9 & 2.3 & 0.1 & 12.3 & 286 & 289 \\
\hline
\end{tabular}

This shows that the degree of saturation actually has effect on the CP of biodiesel. The temperature at which the $\mathrm{CP}$ is attained depends on the sum of $n$-alkane constituent of the fuel, the average size of the $n$-alkane molecules, and their size distribution [16].

Thermodynamic study on cloud point of biodiesel with its fatty acid composition, the correlations of fuel cold properties of biodiesel with its fatty acid composition have been investigated by Imahara [11]. It was found that the CP depends mainly on the quantity of saturated esters and not on the composition of unsaturated ones. Hence, the cold properties of biodiesel fuel made from various feed-stocks can be estimated.

The fact that saturated fatty acids have high MP, while unsaturated ones have low MP, supports this finding, since oils containing much of unsaturated fatty acids (FA) are liquid, whereas, fats with high saturated FA are solid at ambient temperature. However, high level of unsaturation result in a lower MP, and simultaneously, causes high vulnerability to oxidation. This trend causes adverse effects on the combustion and conservation of fuel [11], hence there is need to understand the fatty acid composition as these features of feedstock is taken over by biodiesel fuel. Table 3 summarizes their findings.

As shown in the result, the saturated ester content determines the $\mathrm{CP}$ while the composition of unsaturated ester has negligible effect. Thus, for oxidation stability with no negative influence on fuel cold properties, mono-unsaturated FAME such as C18:1 is regarded as more beneficial than poly-unsaturated FAME such as (C18:2) and C18:3. Source: H. Imahara et al. / Fuel 85 (2006) 1666-1670

In another review, Refaat [17] also observed that, the length of the fatty acid chain as well as its composition plays a substantial role in the cold flow properties of biodiesel.

National Biodiesel Board [18] also stated that these properties of biodiesel fuels depends on the raw material (particular type of grease, fat or oil) from which they are produced, and are a strong factor of the amount of saturated fat.

\subsubsection{Improving Cold Flow Properties}

To address these poor cold flow properties of biodiesel, researchers have also come up with some findings. Krishna and Butcher [19] said that to improve cold flow characteristics; biodiesel should be blended with petro diesel as it is being practiced, additives should be used- though this may not affect cloud point, but could reduce pour point, and also, saturates should be reduced in source material by separation and 'tailoring' biologically.

Dunn [9] reports that fractionation improves cold flow properties of biodiesel by modifying its fatty acid profile to remove high-melting components, with result in reduced crystallization onset temperatures.

On the CFPP, Wang et al. [20] investigated the use of surfactants and detergent fractionation to improve the cold flow properties of biodiesel from waste cooking oil (BWCO). They reported that the CFPP was greatly reduced from $-10^{\circ} \mathrm{C}$ to $-16^{\circ} \mathrm{C}$ by the addition of $0.02 \mathrm{wt} \%$ of poly-glycerol ester.

Winterization which is the process of removing saturated methyl esters by cooling the fuel to cause crystallization and then separating the high melting components by filtration is another method of improving cold flow properties [21]. Pérez, et al. [11] also said that cold flow properties may be improved with different winterization techniques, and the best technique was found to be crystallization filtration using methanol, which reduces the CFPP from $17^{0} \mathrm{C}$ to $-8^{0} \mathrm{C}$ with a biodiesel loss of $8.93 \mathrm{wt} . \%$.

However, Winterization is generally not an efficient way of improving cold flow properties due to the high yield loss. It is also not feasible in many cases to store the high $\mathrm{CP}$ fraction which was separated for use during summer or to transport it to a warmer climate region, so it must be used as a lower-value fuel [21].

Jon Van Gerpen [22] in another research also reported that blending improves cold flow properties of biodiesel, when he blended Tallow and soybean oil based biodiesel with diesel.

Kim et al. [23] in another research examined the cold 
performance of biodiesel blends in a car and a light duty truck at $-16^{\circ} \mathrm{C}$ and $-20^{\circ} \mathrm{C}$, using jatropha, soybean, palm, rapeseed, cottonseed, and waste cooking oil derived biodiesels mixed with different fractions (B5, B10 and B20). They observed that the presence of unsaturated structures and the hydrocarbon chain length has marked effect on the low-temperature properties of biodiesel as the start-ability and drivability of the car with all B5 blends were generally good at $-20^{\circ} \mathrm{C}$. While the $\mathrm{B} 10$ and the $\mathrm{B} 20$ blend of palm biodiesel failed at $-20^{\circ} \mathrm{C}$ and at $-16^{\circ} \mathrm{C}$ respectively in the start-ability test, the B10 and B20 blends of jatropha, soybean, rapeseed and waste cooking tended to be good at $-20^{\circ} \mathrm{C}$ in both tests.

The addition of cold flow improvers coupled with blending, B1, B5, and B20 in most cases enhanced the cold flow properties of soybean and canola biodiesel in the Midwest [13]. Primarily, the additive changes the growth pattern of crystals, by preventing them from growing too big, rather than keeping the biodiesel molecule from crystallizing. The crystals have to grow only up to about $0.5 \mu \mathrm{m}$ to be seen and be recorded as CP, whereas, all the crystals have to stick and solidify at the pour point. Since fuel additives prevent growth patterns and make the crystal harder to adhere, the cold flow additives are in effect better at reducing PP than CP [24].

Like normal diesel fuels, blends of biodiesel in very cold temperatures will gel. This implies that, without the addition of cold flow improvers \#2 diesels will start to gel and plug filters at their cloud point [8].

On the pour point, pour point depressants are used. As stated above, most pour point depressants do not alter the initial formation of the crystals and thus they do not generally affect the cloud point. Instead, they inhibit the crystals from building up to a size large enough to plug filters. They act by surrounding the small crystals and provide a barrier to agglomeration [15].

Good tank upkeep patterns will assure cold weather operability, in that, fuel systems and tanks are sometimes neglected and un-maintained, causing deposit on the filter which pulls glycerin which then plugs the filter. The change of fuel filters before the winter season, and the monitoring and cleaning of tanks when necessary is encouraged; this is to decrease contamination [8].

\subsection{Kinematic Viscosity}

Viscosity is the degree of a material's resistance to flow, high viscous materials flow with great difficulty, while less viscous ones flow with ease [25]. It causes the formation of engine deposits as it affects the atomization of a fuel upon injection into the combustion chamber, the higher the viscosity, the greater the propensity of the fuel to cause such problems [26]. The kinematic viscosity value of the biodiesel decreases with increase in temperature.

The viscosity of a fluid can be expressed as a dynamic viscosity and a kinematic viscosity. Dynamic viscosity is measured in units called centipoise. Kinematic viscosity takes into account the fluid density and is measured in units called centistokes.

The acceptable viscosity range for biodiesel according to ASTM D6751 is between 1.9 and $6.0 \mathrm{~mm}^{2} / \mathrm{s}$. The upper limit for biodiesel is higher than the upper limit for normal diesel fuel $\left(4.1 \mathrm{~mm}^{2} / \mathrm{s}\right)$ and should be taken into account when looking at blends [27].

The viscosity of biodiesel is an important element in the performance of fuel in an engine as both low and high viscosities can have negative effects on an engine's performance. While low viscosities does not provide sufficient lubrication for the precision fit of fuel injection pumps (which results in leakage or increase wear), high viscosities leads to the formation of large droplets on injection (resulting in poor combustion, raised exhaust smoke and emissions) [27].

The high viscosity of biodiesel and its blends alter the pattern of injector spray in the engine, leading to the formation of carbon deposits in the engine, with eventual result in problems such as stuck piston rings in the cylinder and subsequent engine failures. This is caused by fuel impingement on the piston and other combustion chamber surfaces, but with the use of petro-diesel it would rarely occur $[7,28]$.

If fuel viscosity is low, the outflow will correspond to a power loss for the engine and if fuel it is high, the injection pump will be unable to supply enough fuel to fill the pumping chamber. Again, the effect will be power loss. The viscosity range for typical biodiesel fuels overlaps the range for diesel fuel. If fuel viscosity is extremely excessive, as is the case with vegetable oils, there will be a degradation of the spray in the cylinder causing poor atomization, contamination of the lubricating oil, and the production of black smoke [29].

Knothe, [30] also said that high viscosity causes operational problems as a result of poor atomization of the fuel in the engine's combustion chambers.

Predicting the value of viscosity of a biodiesel from the knowledge of its composition, would be helpful in the optimization of biodiesel production processes and the designing of blending of raw materials and refined products.

Standard values set by the European standard and American Society for Testing and Materials are given below;

Table 4. Kinematic viscosity in diesel fuel standards

\begin{tabular}{|c|c|c|c|c|}
\hline Standard & Location & Fuel & Methoda & $\begin{array}{c}\text { Kinematic viscosity } \\
(\mathrm{mm} 2 / \mathrm{s})\end{array}$ \\
\hline $\begin{array}{c}\text { ASTM } \\
\text { D975 }\end{array}$ & $\begin{array}{c}\text { United } \\
\text { States }\end{array}$ & Petro-diesel & $\begin{array}{c}\text { ASTM } \\
\text { D445 }\end{array}$ & $1.9-4.1$ \\
\hline $\begin{array}{c}\text { ASTM } \\
\text { D6751 }\end{array}$ & $\begin{array}{c}\text { United } \\
\text { States }\end{array}$ & Biodiesel & $\begin{array}{c}\text { ASTM } \\
\text { D445 }\end{array}$ & $1.9-6.0$ \\
\hline EN 590 & Europe & Petro-diesel & ISO 3104 & $2.0-4.5$ \\
\hline EN 14214 & Europe & Biodiesel & ISO 3104 & $3.5-5.0$ \\
\hline
\end{tabular}

a. ASTM= American Society for Testing and Materials; ISO, International Standards Organization.

Source: Gerhard Knothe and Kevin R. Steidley, 2005. Kinematic viscosity of biodiesel fuel components and related compounds. Influence of compound structure and comparison to petrodiesel fuel components 
The Influence of compound structure on Kinematic viscosity of biodiesel fuel components and related compounds as compared to petro-diesel fuel components was investigated by Knothe and Steidley [31]. Influencing factors were found to be length of chain, position/number, and type of bonds, as well as nature of oxygenated moieties.

The research proved that the kinematic viscosity increases with length of chain of either the fatty acid or alcohol moiety in a hydrocarbon, and that the increase in kinematic viscosity over a certain number of carbons is smaller in straight chain hydrocarbons. To this end, the kinematic viscosity of unsaturated fatty compounds strongly depends on the type and number of bonds. Double bonds at the end of straight chain hydrocarbons have a minimal reducing effect on the viscosity $[31,32]$.

In an Experimental Investigation on the Fuel Properties of Biodiesel and Its Blends at Various Temperatures by Yoon [7], the viscosity of the tested fuels was seen to decrease in proportion to decreasing blending ratio and increasing temperature.

\subsubsection{Improving the Kinematic Viscocity}

Since the kinematic viscosity is a measure of a fluid's resistance to flow over time, ways of improving it has been established by researchers. The finding of kinematics viscosity gives very good parameter for conformity with ASTM standards [33].

In the Thermodynamic and Viscometric Evaluation of Biodiesel and Blends from Olive Oil and Cashew Nut Oil, Okoro et al. [34] said that blending biodiesel with petro-diesel can be done to correct viscosity values to favor utilization in engine system.

The result of Moradi, et al. [35] also showed that increasing the biodiesel volume fraction in biodiesel -diesel blends increases the kinematic viscosity, thus volume of blend should be considered.

\section{Conclusions}

Cold flow properties (CP, PP and CFPP) and the kinematic viscosity of biodiesel have been reviewed, and the nature of feedstock has been found to influence these properties.

Saturated esters, which have higher CP than unsaturated ones, have a marked influence on qualifying cold properties. Within the Biodiesel family, cloud points can be correlated to the fraction of saturated compounds. The cold flow is better with lower fraction of saturates, though this might affect stability.

The work of Tat and Gerpen, [36] indicate that all fuels have similar behavior. At temperatures approaching the beginning of crystal formation, the viscosity rapidly increases, and the viscosity of the blends changes between biodiesel and the diesel fuels depending on their ratio.

Kinematic viscosity is a significant criterion of the biodiesel's flow properties, as high viscosity is found to be linked with engine deposits and poor atomization of the fuel spray from the injectors. Because of the consequence that high viscosities can have on injector spray functioning, it should be given consideration in the production of biodiesel and it should remain a part of the specification [4].

On improving these properties, blending with petro-diesel or more saturated biodiesel, and the use of additives have been shown to significantly affect cloud and pour point. Though, additives may not reduce cloud point, it prevents the crystals from agglomerating.

With the opposing requirements between cold temperatures flow characteristics and oxidative stability and NOx emissions, there is no fatty acid profile that will provide a fuel with these parameters at optimum. One should therefore consider a fuel high in the monounsaturated fatty acids, and low in both saturated and polyunsaturated fatty acids.

The accurate knowledge of the influence of the molecular structure on these properties would help in the selection of oils whose composition will give the optimal performance. Viscosity is influence by elements such as the configuration of the double-bond; cis-double bond configuration gives lower viscosity than trans, while the position of double-bond has less effects on viscosity [26].

If cold attributes can be predicted, eliminating difficult measurements can be practicable and appropriate selection of feedstock will be done to yield biodiesel that conforms to specifications. Since CP is the initiation for adverse effect on fuel injection, predicting it is highly significant.

\section{REFERENCES}

[1] Biodiesel (n.d.). In Wikipedia. Retrieved June 12, 2013, http://en.wikipedia.org/wiki/Biodiesel

[2] Marzena Dzida and Piotr Prusakiewicz. (2008). The effect of temperature and pressure on the physicochemical properties of petroleum diesel oil and biodiesel fuel. Fuel 87 (2008), Issues 10-11, 1941-1948.

[3] Evangelos G. Giakoumis, (2013). A statistical investigation of biodiesel physical and chemical properties, and their correlation with the degree of unsaturation. Published in "Renewable Energy", Vol. 50, pp. 858-878, 2013.

[4] Kinast J.A., (2003). Production of Biodiesels from Multiple Feedstocks and Properties of Biodiesels and Biodiesel/Diesel Blends. Final Report. National Renewable Energy Laboratory, NREL/SR-510-31460.http://www.biofuels.coop/archive/biod iesel_report.pdf

[5] Sven O. Gärtner and Guido A. Reinhardt, (2005). Environmental Implications of Biodiesel (Life-Cycle Assessment). Gerhard Knothe, Jon Van Gerpen and Jürgen Krahl, (Eds). The Biodiesel Handbook, 2nd Edition. Pp 210-221. ISBN: 978-1-893997-62-2.

[6] Steve Howell and Joe Jobe, (2005). Current Status of Biodiesel in the United States. Gerhard Knothe, Jon Van Gerpen and Jürgen Krahl, (Eds). The Biodiesel Handbook, 
2nd Edition. Pp 181-191. ISBN: 978-1-893997-62-2.

[7] Seung Hyun Yoon, Su Han Park, and Chang Sik Lee, (2008). Experimental Investigation on the Fuel Properties of Biodiesel and Its Blends at Various Temperatures. Energy \& Fuels, 22, 652-656

[8] Ralph Groschen, (2009). Petroleum Diesel Fuel and Biodiesel Technical Cold Weather Issues. Report to the Legislature. Minnesota

department of agriculture. Retrieved June 12, 2013, from, htt p://www.mda.state.mn.us/news/publications/renewable/biodi esel/biodieselcoldissues.pdf

[9] Worldwide Fuel Charter (WWFC) Committee, (2009). Biodiesel Guidelines. Retrieved June 12, 2013, from,http://www.truckandenginemanufacturers.org/file.asp

[10] Dunn O. Robert. (2011). Improving the Cold Flow Properties of Biodiesel by Fractionation, Soybean -Applications and Technology, Prof. Tzi-Bun Ng (Ed.), ISBN: 978-953-307-207-4, InTech, Available

from:http://www.intechopen.com/books/soybean-application s-and-

technology/improving-the-cold-flow-properties-ofbiodieselby-fractionation.

[11] Pérez A, Casas A, Fernández CM, Ramos MJ, and Rodríguez L. (2010). Winterization of peanut biodiesel to improve the cold flow properties. Bioresour Technol. 2010 Oct;101(19):7375-81. doi: 10.1016/j.biortech.2010.04.063. Epub 2010 May 23.

[12] Imahara Hiroaki, Minami Eiji, and Saka Shiro. (2006). Thermodynamic study on cloud point of biodiesel with its fatty acid composition. Fuel 85 (2006) 1666-1670, Elsevier Science available on line on science direct.

[13] Shawn P. Conley (2012). Biodiesel Quality: Is All Biodiesel Created equal? BioEnergy. ID-338. Purdue extensionhttp://www.extension.purdue.edu/extmedia/ID/ID338.pdf from http://www.ces.purdue.edu/bioenergy

[14] Enweremadu C. C., Rutto H. L. and Oladeji J. T. (2011).Investigation of the relationship between some basic flow properties of shea butter biodiesel and their blends with diesel fuel. International Journal of the Physical Sciences Vol. 6(4), pp. 758-767, 18 February, 2011. DOI: 10.5897/IJPS10.553 ISSN 1992 - 1950.

[15] National Biodiesel Education Program, (n.d). Diesel Fuel Cold Flow Properties. Biodiesel Shortcourse - Cold Flow, Biodiesel Education. Retrieved June 12, 2013, from http://web.cals.uidaho.edu/biodiesel/biodiesel-shortcourse-co ld-flow/

[16] Fátima I.C. Mirante and João A.P. Coutinho, (2001). Cloud point prediction of fuels and fuel blends. Fluid Phase Equilibria 180 (2001) 247-255

[17] Refaat A. A., (2009). Review Paper. Correlation between the chemical structure of biodiesel and its physical properties. Int. J. Environ. Sci. Tech., 6 (4), 677-694, Autumn 2009. ISSN: $1735-1472$

[18] National Biodiesel Board. (2007/2008). Biodiesel Cold Flow Basics. Information for Petroleum Distributors, Blenders, and End-Users on Issues Affecting Biodiesel in the Winter Months. Retrieved June 12, 2013,

fromwww.biodiesel.org/docs/ffs-performace_usage/cold-flo w-basics---ppt!.
[19] Krishna C.R., Butcher Thomas, Mahajan Devinder, Thomassen Kaitlin and Brown Christopher. (2008). Improving cold flow

properties of biodiesel. Retrieved June 12, 2013, from http:// www.aertc.org/conference/AEC Sessions $\% 5$ CCopy $\% 20$ of $\%$ 20Session $\% 202 \% 5$ CTrack $\% 20 \mathrm{~B} \% 20$ Renewables $\% 5 \mathrm{C} 1 . \% 20$ Climate\%20Change\%20Biofuels\%20III\%5C1.\%20Dr.\%20C R\%20Krishna\%5CCR\%20Krishna\%20presentation.pdf

[20] Yong Wang, Shun Ma, Mouming Zhao, Lina Kuang, Jieyu Nie and William W. Riley. (2011). Improving the cold flow properties of biodiesel from waste cooking oil by surfactants and detergent fractionation. Fuel 90 (2011) 1036-1040) journal homepage: www.elsevier.com/locate/fuel

[21] John Nowatzki, Dev Shrestha, Andrew Swenson, and Dennis P. Wiesenborn, (2012). Biodiesel Cloud Point and Cold Weather Issues. Jon Van Gerpen, Joel Schumacher, Reviewers. Retrieved June 12, 2013, fromhttp://www.extension.org/pages/26611/biodiesel-cloudpoint-and-cold-weather-issues

[22] Jon Van Gerpen, (n.d). Cold Flow Properties of Blends of Tallow and Soybean Oil-based Biodiesel. WHITE PAPER. Crimson renewable energy, LP. Retrieved June 12, 2013, from http://www.crimsonrenewable.com/UofIdaho.php.

[23] Kim J. -K., Yim E. S., Jeon C.H, Jung C. -S., and Han B. H., (2012). Cold performance of various biodiesel fuel blends at low temperature. Abstract. International Journal of Automotive Technology, 2012, Volume: 13, Issue 2, 293-300.DOI.10.1007/S12239-012-0027-2

[24] Shrestha D. S., Gerpen J. Van and Thompson J. (2008). Effectiveness of cold flow additives on various Biodiesels, diesel, and their blends. American Society of Agricultural and Biological Engineers ISSN 0001-2351, Vol. 51(4): 1365-1370_2008

[25] Linus N. Okoro, Sedoo V. Belaboh, Nwamaka R. Edoye, Bello Y. Makama. (2011). Synthesis, Calorimetric and Viscometric Study of Groundnut oil Biodiesel and Blends. Research Journal of Chemical Sciences Vol. 1(3) June (2011) ISSN 2231-606X 49

[26] Knothe Gerhard, (2005b). Viscosity of Biodiesel. Gerhard Knothe, Jon Van Gerpen and Jürgen Krahl, (Eds). The Biodiesel Handbook, 2nd Edition. Pp 89-90. ISBN: 978-1-893997-62-2.

[27] Cennatek Bioanalytical Services, (2013). Kinematic Viscosity According to ASTM D445. Retrieved June 13, 2013, from http://cennatek.ca/analytical/biodiesel/kinematicviscosity-according-to-astm-d445/.

[28] Samuel V. D. Freitas, Maria Jorge Pratas, Roberta Ceriani, Alvaro S. Lima, and João A. P. Coutinho, (2010). Evaluation of Predictive Models for the Viscosity of Biodiesel. Energy Fuels 2011, 25, 352-358. DOI:10.1021/ef101299d

[29] Gerpen Van Jon, (2005). The Basics of Diesel Engines and Diesel Fuels. Gerhard Knothe, Jon Van Gerpen and Jürgen Krahl, Editors. The Biodiesel Handbook, 2nd Edition. Pp 25-33. ISBN: 978-1-893997-62-2.

[30] Knothe Gerhard, (2005a). The History of Vegetable Oil-Based Diesel Fuels. Gerhard Knothe, Jon Van Gerpen and Jürgen Krahl, (Eds). The Biodiesel Handbook, 2nd Edition. Pp 12-24. ISBN: 978-1-893997-62-2

[31] Knothe Gerhard and Steidley R. Kevin, (2005). Kinematic 
viscosity of biodiesel fuel components and related compounds. Influence of compound structure and comparison to petrodiesel fuel components. Fuel 84 (2005) 1059-1065. Elsevier.nl

[32] Knothe Gerhard. (2005c). Dependence of biodiesel fuel properties on the structure of fatty acid alkyl esters. Fuel Process Technol 2005; 86:1059-70.

[33] Babagana Gutti, Shittu S. Bamidele and Idris M. Bugaje. (2012). Biodiesel kinematics viscosity analysis of Balanite aegyptiaca seed oil. ARPN Journal of Engineering and Applied Sciences, Vol. 7, no. 4, April 2012 ISSN 1819-6608

[34] Linus N. Okoro, Fadila I. Sambo, Mukhtar Lawal and
Clifford Nwaeburu. (2011b). Thermodynamic and Viscometric Evaluation of Biodiesel and Blends from Olive Oil and Cashew Nut Oil. Research Journal of Chemical Sciences, Vol. 1(4), 90-97, July (2011) ISSN 2231-606X

[35] Moradi G. R., Karami B., and Mohadesi M. (2013). Densities and Kinematic Viscosities in Biodiesel-Diesel Blends at Various Temperatures. Journal of Chemical and Engineering Data dx.doi.org/10.1021/je3008843 | J. Chem. Eng. Data 2013, 58, 99-105

[36] Mustafa E. Tat and Jon H. Van Gerpen, (1999). The Kinematic Viscosity of Biodiesel and Its Blends with Diesel Fuel. JAOCS, Vol. 76, no. 12 (1999). Paper no. J9166 in JAOCS 76, 1511-1513 (December 1999). 